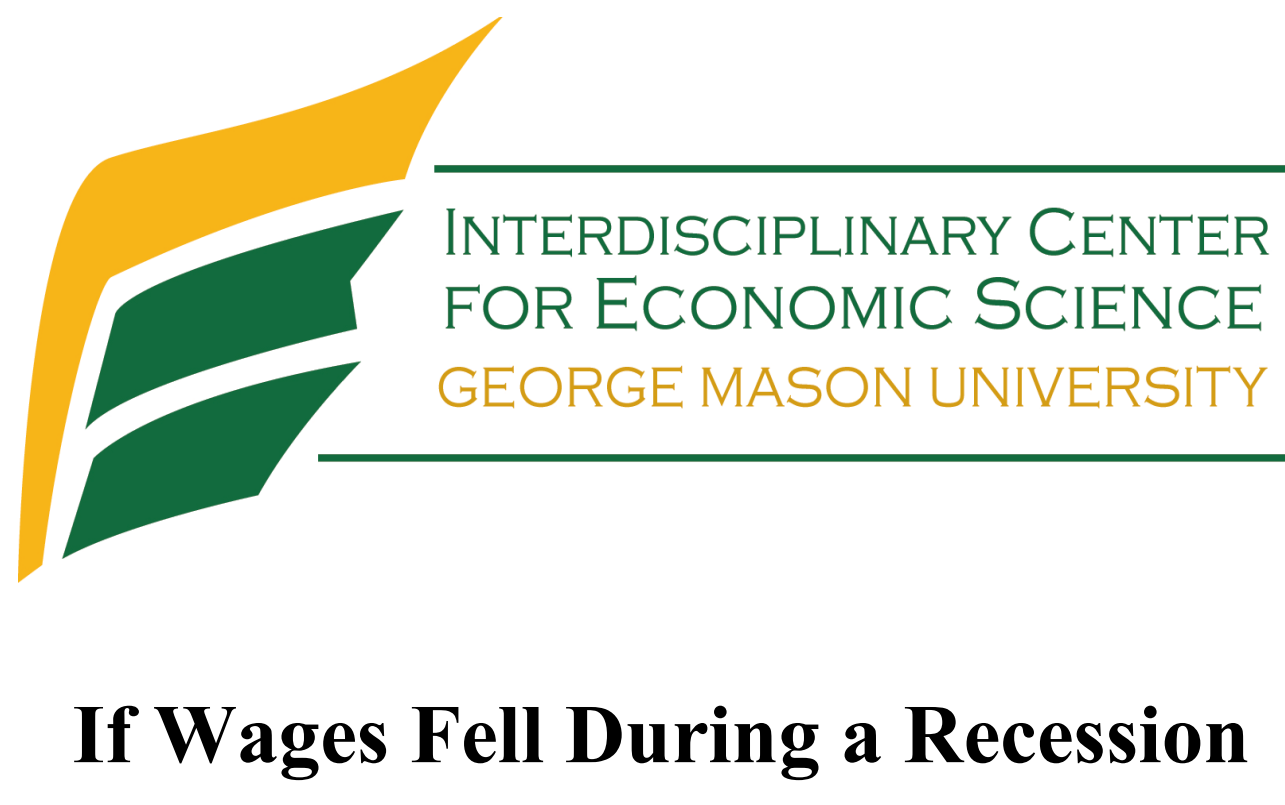

Joy Buchanan and Daniel Houser

June 2019

Discussion Paper

Interdisciplinary Center for Economic Science

4400 University Drive, MSN 1B2, Fairfax, VA 22030

Tel: +1-703-993-4850 Fax: +1-703-993-4851

ICES Website: http://ices.gmu.edu

ICES RePEc Archive Online at: http://edirc.repec.org/data/icgmuus.html 


\title{
If Wages Fell During a Recession
}

\author{
Joy Buchanan and Daniel Houser *
}

May 2019

\begin{abstract}
Many economies exhibit downward wage rigidity. Surveys of managers indicate that employers hold wages rigid because they believe morale will suffer after a wage cut. Otherwise, there is little evidence for how employers' beliefs contribute to wage rigidity and whether those beliefs are accurate. Our design allows us to compare beliefs and effort rigorously. We demonstrate that effort falls after workers experience a wage cut and also that workers form reference points from wage contracts. Despite this partial confirmation of the morale theory as an explanation for wage rigidity, half of the employers in our experiment cut wages and lose money as a result. In a treatment where a recession is offset by nominal inflation, real wage cuts do not have a significant effect on effort. (JEL codes: C91, D84)
\end{abstract}

\section{Introduction}

Why do we observe high unemployment during a recession instead of wage cuts? Nominal wage cuts were rare during the Great Recession in the US economy (e.g., Daly and Hobijn [2014]) and are uncommon in most countries (Dickens et al. [2007] provide an international comparison). ${ }^{1}$ There is extensive data on downwardly rigid wage contracts but very little evidence from the counterfactual: what happens if wages fall?

One cause of wage rigidity advanced by Akerlof et al. [1996] is that managers do not cut wages because they expect that wage cuts will lower worker morale and thereby reduce productivity. Bewley [1999] presented evidence supporting the morale theory from interviews with industry managers who said they believe that workers retaliate against wage cuts. The goal of this paper is to provide data at the individual level to test the morale theory of wage rigidity in an environment that eliminates the confounds of menu costs.

In a controlled experiment, we observe the wage level set by an employer and the effort level chosen by workers in response to their wage. In the Recession treatment, the available surplus shrinks such that an employer may feel justified in cutting wages to share the impact of the adverse event. In an additional treatment, the recession is offset by nominal inflation, so that we can compare the reaction to real versus nominal wage cuts. The outcome of monetary policies often depends on how nominal and real wage cuts are

\footnotetext{
*Brock School of Business, Samford University, Birmingham, AL, USA, jbuchan1@samford.edu; George Mason University, 4400 University Drive, MSN 1B2, Fairfax, VA 22030, USA, dhouser@gmu.edu

${ }^{1}$ Daly and Hobijn [2014] use the Current Population Survey data to show that the number of wage freezes increased after the Great Recession. The distribution of wage changes implies that firms were avoiding wage cuts by keeping wages rigid. They are able to replicate this data pattern using a model in which some percent of workers cannot renegotiate their wage contract in a given period. Our research question is why it appears that many employment contracts cannot be renegotiated and what common characteristics rigid agents might share. Schmitt-Grohé and Uribe [2016] document that nominal wages are downwardly rigid in emerging countries.
} 


\section{RELATED LITERATURE}

perceived by workers. Employers make incentivized predictions that we compare to the actual behavior of workers, which allows us to examine whether the beliefs of employers drive wage rigidity.

Our findings corroborate recent studies that show labor supply is affected by reference points. Gächter and Thoni [2010] and Bracha et al. [2015] provide experimental evidence that workers reduce effort if they learn that they are earning less than their peers. Workers in a field experiment by Kube et al. [2013] reduce the number of books they catalog for a library after their wage is cut relative to what was indicated in the job advertisement. In many of these studies, the wage is set by the experimenter. In our experiment, the wage is set by another participant and we provide no reference point aside from experience in past contracts with that counterpart. We find that workers react negatively to wage cuts. If employers reduce the wage, after a 3-round fixed-wage contract, the worker they are matched with often reciprocates with a reduction of effort.

This paper presents a novel test of whether workers retaliate against wage cuts when the wage is endogenous and whether employers have correct beliefs about the effect of wage cuts. We review relevant literature in the following section. We explain the experimental design in section 3. In Section 4, we present a theory of wage-setting that incorporates beliefs employers hold about worker reciprocity. Results are presented in Section 5 and we conclude in Section 6.

\section{Related Literature}

Several previous studies have addressed the question of how wage changes affect individual effort choices. The most relevant papers examine wage cuts specifically; and there is a disagreement in the literature as to whether wage cuts always lead to lower effort. Previous experiments on wage cuts vary greatly in design. For example, in some cases wages are manipulated by another human subject and sometimes wages are changed exogenously by the experimenter.

There is consistent evidence that workers modulate their effort based on how they perceive the intentions of their employers toward them. Charness [2004] tests whether workers react only to their monetary wages or whether the intentionality of the employer matters. He found that workers punish low wages that were intentionally set by employers. If an exogenous device (a bingo cage draw or the experimenter), selects a low wage, the workers did not cut their effort so dramatically. The workers did not want to punish the employer for a wage that was out of their control. Charness found "considerable negative reciprocity" displayed toward an individual employer who is a peer and whose earnings depend on the effort level.

Several studies demonstrate reference-dependent behavior among workers. DellaVigna et al. [2017] provide evidence from a natural experiment in Hungary that workers anchor their expectations around recent paychecks. Diriwächter and Shvartsman [2018] show that reported job satisfaction in Germany increases when workers receive a wage increase. This complements the experimental evidence from Sliwka and Werner [2017] that effort is higher when workers receive wage increases. In a controlled experiment, Sliwka and Werner hold total compensation constant and demonstrate that increasing wage profiles are profitable for firms because it encourages high (unobservable) effort from employees.

Exactly which circumstances make wage cuts painful is important to understand. Experiments are particularly useful in this pursuit. Chen and Horton [2016] find that workers in online labor markets naturally form reference points and quit tasks when they encounter wage cuts. However, workers are not upset if they provide a reasonable explanation for wage cuts. When an explanation is perceived as reasonable, the employer might not seem to be at fault or even in control.

Without providing an explanation, Kube et al. [2013] give workers $\frac{2}{3}$ of the wage that they had expected from the wording in the advertisement for the experiment. The disappointment results in a $20 \%$ decline in effort. DellaVigna et al. [2016] implement a pay cut of a similar proportion and do not find the effect. DellaVigna et al. cycle workers through three different pay schemes in which workers do a real task for three different charities (all within the one-time experimental session). Perhaps the exposure to changes mentally prepared the workers to accept a wage cut during the final rounds. Wages are more flexible when workers expect changes or conditional bonuses. Wage flexibility was observed by Gerhards and Heinz (2017) in a paper closely related to ours. They implement a recession after one period of gift exchange through 


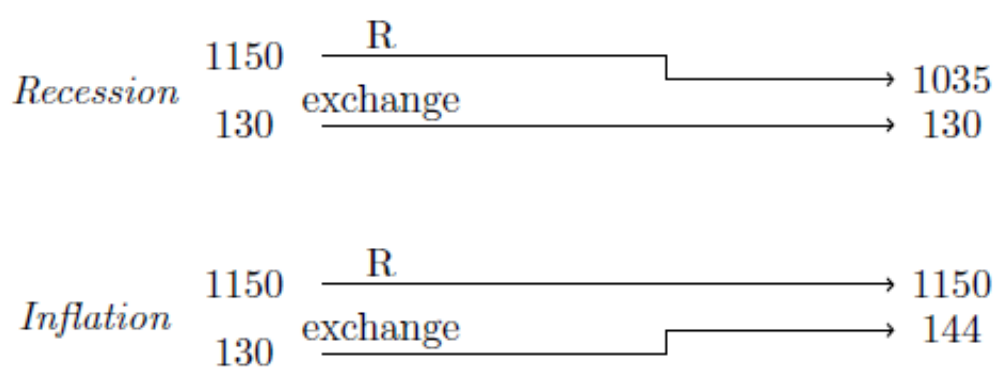

Round $\begin{array}{lll}1 & 2-4 & 5-7\end{array}$

Figure 1: Timeline of Parameters in each Treatment

a $50 \%$ decrease in the workers marginal productivity. Workers in their experiment do not retaliate against wage cuts, which is also observed by Linardi and Camerer [2012]. Our findings are more in line with Kube et al. [2013]. We expose workers to the same wage for several consecutive rounds in order to establish an expectation that mirrors the experience of many full-time long-term employees.

To our knowledge, we are the first to measure the beliefs of employers and compare them to effort. Employers' expectations drive wage setting. Our primary contribution is to investigate the effects of loss aversion and beliefs on wage rigidity, which is a significant and novel step toward understanding why wages are usually downwardly inflexible during recessions.

\section{Experimental Design}

Our experiment is designed to allow precise measurement of individual effort. ${ }^{2}$ That measure can be compared with the beliefs employers report about how workers will behave after a wage change. Subjects play a modified gift exchange game (following Fehr et al. [1993]) for 7 rounds with the same partner.

\subsection{Gift Exchange}

At the beginning of each round, the employer sets a nominal wage, $n \in[3, R]$, where $R$ is an exogenous constant. The real wage, $w$, is the nominal wage divided by the exchange rate, initially set at $130 \mathrm{ECUs} / \$$ (Experimental Currency Units). The worker's payment for a round is $w-c(e)$. They pay the explicit cost, $c(e)$, of the effort level they choose, $e \in\{0.05,0.1, \ldots, 1\} .{ }^{3}$ The cost of effort increases from one cent for the minimal effort level to $\$ 0.80 .{ }^{4}$ A table of effort costs is in the instructions in Appendix C.

In nominal terms, the employer earns $(R-n) * e$. The wage is presented to both employers and workers in nominal terms and the exchange rate is explained in the instructions. After the worker responds with an effort level choice, each round ends with a feedback stage where players learn their nominal profit and the

\footnotetext{
${ }^{2}$ Specifically, we measure "unobservable" effort that relies on good morale. At the end of the experiment, workers can shirk if they choose. That is why employers cannot fire workers and the game is not repeated. Brown et al. [2012] find that reciprocity persists in the gift exchange game even when there is excess demand for labor. Our design differs from other experiments that pay a piece-rate wage for effort (i.e. Doerrenberg et al. [2016] conduct an on-line experiment and find an asymmetric response in labor supply to lowering the piece-rate wage).

${ }^{3}$ We did not provide a real-effort task, in part because Erkal et al. [2018] and others have demonstrated that we would have needed to provide an alternative task.

${ }^{4}$ It is possible for workers to be constrained in their choice by a very low wage. Neither the employer nor the worker is allowed to lose money.
} 
Figure 2: Screenshot of New Information Stage

You have just completed round 4 of the experiment. There are 3 more rounds remaining. There is a change in the experiment for the following 3 rounds. The profit calculation for employers will be (1035-wage)*effort. The exchange rate remains $130 \mathrm{ECU}$ per dollar.

Click OK to continue

employer learns the effort level chosen by the worker. We use the terms employer and firm interchangeably in this paper. The subjects only saw 'employer' and 'employee' to denote their roles throughout the experiment.

The first round is a paid practice round. Next, there is a 3-round fixed-wage contract. Workers can set a new effort level in each round but employers only select a wage in round 1, 2, and 5 . Between rounds 4 and 5 , subjects view information about experiment parameters which is different from the original parameters.

Figure 1 shows a timeline of how parameters change in treatments Recession and Inflation. All treatments use identical instructions and are the same until the information stage after round 4.

Figure 2 provides a screenshot of the announcement subjects see during the information stage of the Recession treatment.

In the Recession treatment, employers are confronted with a shrinking pie to share between themselves and the worker they are matched with. By the theory of inequality aversion, both the employer and the worker might decide that it is appropriate to share the impact of this adverse event. However, if workers anchor their expectations around their previous nominal wage contract, then workers may perceive a wage cut as unkind and reciprocate with an unkind reduction in effort.

Worker morale is an important issue to firms because workers cannot be monitored perfectly. In our experiment, a worker who had been cooperating can drop their effort level after round 4 without any fear of retribution. We allow for a fall in productivity to be possible because that is what managers ostensibly want to avoid by keeping wages rigid. Campbell and Kamlani [1997] found in a survey of 184 firms that managers believe a $10 \%$ wage cut would lead to more than a $10 \%$ reduction in effort. We choose a recession size of $10 \%$ for our design to be comparable to this survey.

The parameters are such that, if an employer sets a wage in round 2 and keeps that wage "rigid" by setting the same wage in round 5, the employer would absorb all the loss in Recession. If the employer keeps wages nominally rigid in Inflation, the worker would experience a real wage cut because the price level increases. ${ }^{5}$ The cost of effort is presented in real terms, so it does not change in Inflation.

\footnotetext{
${ }^{5}$ Introducing a similar one-time change in the price level has a large effect on the real trading price of assets in an experiment by Noussair et al. [2012], which they explain as sellers resisting nominal losses.
} 


\subsection{Belief Elicitation}

In round 5, employers set the final wage level and the employee choses an effort level. Before the profits and effort level is reviewed, subjects read a new page of instructions for the belief elicitation. Subjects learn the following history about a worker who is in their session but who is not in their pair: wage and effort in round 4 , and wage in round 5 . This is the first time in the experiment that subjects learn anything about a subject outside their own employer/worker pair.

After learning the history of another worker, subjects guess the effort level that this worker chose in round 5. If they guess correctly, they earn an additional $\$ 2$ at the end of the experiment. The purpose of this design is to better understand why firms choose wage offers and we expect that beliefs play an important role in that decision.

\subsection{Procedures and Subjects}

Subjects were recruited from the student population of a large US state university through an email recruitment system. The experiment was conducted at visually isolated computer terminals using ztree software [Fischbacher, 2007]. The instructions are in Appendix C. During the instruction phase, subjects had several practice tasks that they did on the computer. All subjects entered a wage and effort level and then calculated the profit for a hypothetical employer based on those choices. They had a calculator available for this stage. This familiarized them with the interface and the employer profit function.

After the experiment, subjects completed a short questionnaire. In response to the survey about race, $33 \%$ selected white. More than half of subjects reported having a part-time job and $54 \%$ of subjects were female.

For a loss aversion elicitation after the experiment, subjects made 6 yes-or-no choices. They could choose to participate in up to 6 lotteries that involve a risk of losing money (following Gächter et al. [2007]). To determine which of the lotteries would be played, a volunteer rolled a 6 -sided die. The volunteer flipped a coin to determine the outcome of the lottery.

There were 272 subjects in the experiment; 140 subjects participated in the Recession treatment and 132 in Inflation, and no subject participated in more than one treatment. Subjects were paid a $\$ 5$ show-up fee in addition to their lottery earnings (if any) and what they earned in the experiment (on average $\$ 16$ ). Every round was paid. The experiment lasted about 75 minutes, including payment.

\section{Model and Hypotheses}

There is no monetary incentive for workers to reciprocate above-minimum effort in exchange for high wages, especially in the endgame after the final wage has been set. However, we expect a positive correlation between wages and effort; this reciprocal behavior has been replicated many times (e.g., Brandts and Charness [2004]; Hannan et al. [2002]). Therefore, we model a worker with the following utility function:

$$
U_{t}=w_{t}-c\left(e_{t}\right)+\frac{\alpha}{1+\lambda_{t}} * w_{t}^{\beta} * e_{t}
$$

where $\alpha \geq 0$ and $\beta>0$ are parameters that allow reciprocating high effort for high wages. The real wage in time $t$ is $w_{t}$ and $c\left(e_{t}\right)$ is the real cost of effort. The cost function has the usual form: $c(0)=0, c^{\prime}>0, c^{\prime \prime}>0$. The last term predicts that the second mover (worker) in the game helps the first mover (employer) if the worker feels that she has been treated well. Our concept of reciprocity follows Cox et al. [2007]. In our experiment, the cost function is specifically $c(e)=0.8 e^{1.5}$ which we will use for the example going forward.

The loss aversion parameter, $\lambda$, is forced to zero at the initial stage $t=0$ and also if the worker did not experience a wage cut. Using the nominal wage in the previous period, $n_{t-1}$, as a reference point, the loss aversion function is defined as

$$
\lambda_{t}=\left\{\begin{array}{llc}
0 & \text { if } & n_{t} \geq n_{t-1} \text { or } t=0 \\
\lambda & \text { if } & n_{t}<n_{t-1}
\end{array}\right.
$$


In the initial stage, without loss aversion and using our specific cost function, the workers best-response effort function is

$$
\hat{e}\left(w_{0}\right)=\frac{\alpha^{2}}{1.44} * w_{0}^{2 \beta} .
$$

The elasticity of effort in response to wage is $2 \beta$.

The nominal wage, $n$, is the real wage divided by the price level. Since the employer usually has to choose a nominal wage, we will use $n$ for the decision variable of the employer. The initial nominal wage is $n_{0}$. Paired with this worker, an employer maximizes profit by setting the wage according to

$$
n_{0}^{*}=\frac{\beta R_{0}}{\beta+\frac{1}{2}} .
$$

The profit-maximizing wage depends positively on $R$. Thus, if $R$ falls, which we will call a recession, $n^{*}$ also falls. Absent concerns about loss aversion, wages should fall in a recession.

If the interaction proceeds past the initial stage, then the choices in the initial stage could affect the way a worker evaluates if she has been treated well. ${ }^{6}$ If the subsequent wage, $n_{1}$, is less than the initial wage, $n_{0}$, then the worker might experience a sense of loss measured by $\lambda .^{7}$

The effort function accounting for loss aversion is

$$
\hat{e}\left(w_{t}\right)=\left(\frac{\alpha}{1.2\left(1+\lambda_{t}\right)}\right)^{2} * w_{t}^{2 \beta} .
$$

If $\lambda$ is larger than some threshold value $\underline{\lambda}$, it is not profitable to cut wages in a recession, because effort would fall and total profit would be lower than if the wage stays fixed. The value of $\underline{\lambda}$ is derived in Appendix $\mathrm{B}$, along with the derivations of the optimal effort and wage functions. The optimal wage for the employer to set, allowing for loss aversion is

$$
n^{*}=\left\{\begin{array}{ccc}
n_{t-1} & \text { if } & \lambda_{t}>\underline{\lambda} \\
\frac{\beta R_{t}}{\beta+\frac{1}{2}} & \text { if } & \lambda_{t} \leq \underline{\lambda}
\end{array}\right.
$$

Figure 3 illustrates an example. Figure 3 plots the firm profit as a function of the nominal wage offer, assuming that the firm faces a worker who uses $\hat{e}(w)=\frac{0.3^{2}}{1.44} * w_{0}^{2 * 0.2}$ as an effort response function. The higher blue line shows this function at $R=1150$ and the profit maximizing nominal wage is marked by the vertical line at 328. The parameters $\alpha=0.3$ and $\beta=0.2$ remain constant in the example.

If $R$ falls to 1035, as it does in the experiment, then the optimal wage falls to 296 marked by the dot in Figure 3. The height of the dot indicates the highest profit the firm could make after a fall in $R$ if the worker is not loss averse. The dashed line shows the profit to the firm if the wage is cut and the worker is loss averse, supposing $\lambda=1.1$. Effort falls by so much after a wage cut that the profit-maximizing strategy for this firm after the recession is to keep nominal wages rigid.

Our experiment is designed to test the following main hypotheses:

Hypothesis 1: Workers will reduce effort if they experience a nominal wage cut. Specifically, they will give less effort per wage received, thus, $H_{A}: \lambda>0$.

Hypothesis 2: Anticipating hypothesis 1, employers will avoid nominal wage cuts.

We expect hypothesis 2 to hold in Recession, although alternative theories of fairness suggest that wages should fall after a recession.

Additionally, we can compare the effect of real wage cuts when they are masked by inflation. Whether workers are more sensitive to nominal or real wage cuts is an empirical question left open by Dickens et al.

\footnotetext{
${ }^{6}$ If we suppose, like Kőszegi and Rabin [2006], that agents have a reference point based on (rational) expectations then this paper contributes to answering the question of how those expectations are formed. Do workers expect that their wages will stay the same, regardless of changing economic conditions?

${ }^{7}$ The resulting best-response effort function would be the same if $\lambda$ is inserted as follows: $U=w-c(e) *(1+\lambda)+\alpha * w^{\beta} * e$. In that presentation, experiencing a wage cut increases the "cost" of working.
} 


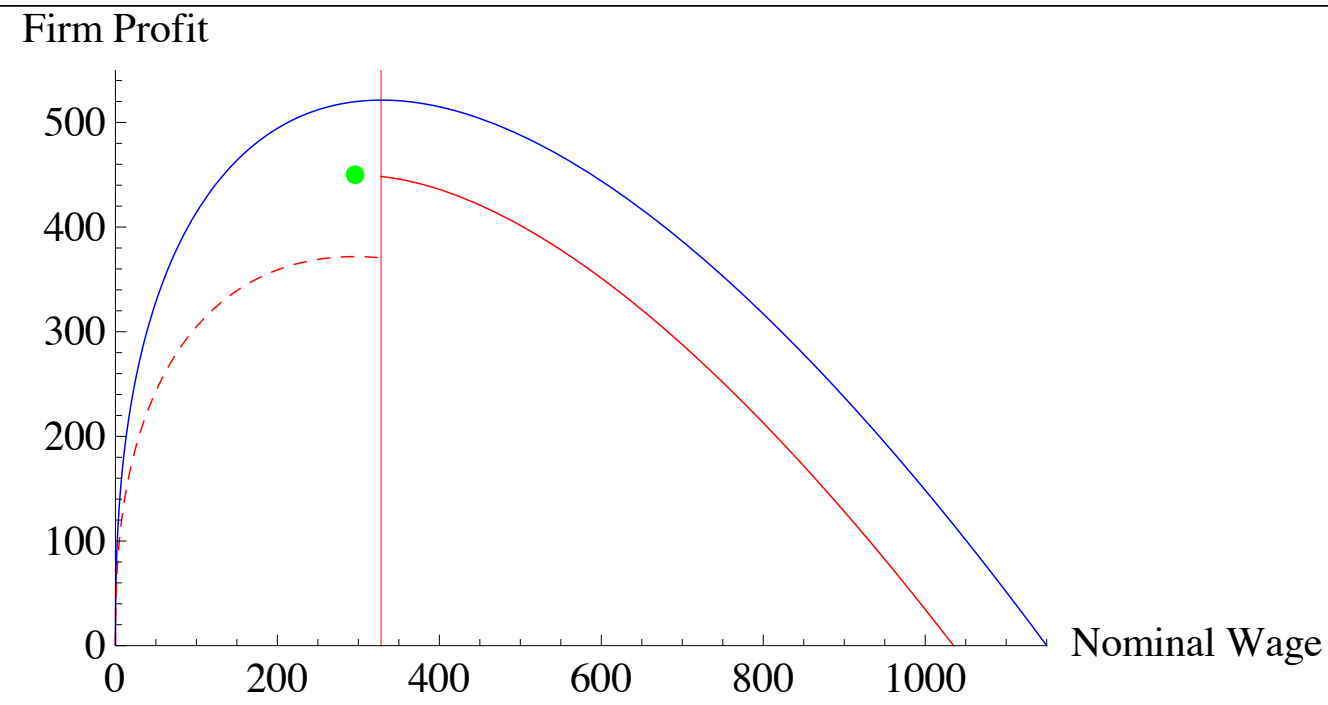

Figure 3: Firm Profit Before and After a Recession

[2007] who found that nominal wages in the U.S. are rigid downward but that countries like the U.K. exhibit considerable real rigidity.

Hypothesis 3: When given the opportunity in the Inflation treatment, employers will avoid nominal wage cuts but allow real wages to fall.

\section{Results}

In the following section we present evidence that wage cuts cause workers to reduce effort, which lowers the profits of firms. The subsequent sections contain the results of the incentivized belief elicitation and loss aversion elicitation. Beliefs and loss aversion both help to explain the choice of the employer to cut wages.

\subsection{Main Results for Wages and Effort}

It is evident in Figure 4 that positive reciprocity is operating in round 4, before the information stage differentiates the treatments. The number of workers in each wage bin is indicated in the graph. Workers with higher wages work harder. It is essential for this experiment that at least some of the subjects be operating with "good morale" before the negative shock. The average effort between treatments is similar in round 4 (a t-test indicates no difference). Figure A1 shows average effort in each round, by treatment.

It appears that many workers who received any wage higher than $\$ 2$ felt that their wage was fair or adequate and they reciprocated with an effort level near the middle of the feasible effort range. That wage contract forms a reference point for workers. Four workers who received a wage above $\$ 6$ are not pictured in Figure $4^{8}$.

About half of the workers in Recession treatments experience a nominal wage cut. The second row of CDFs in Figure 5 show the change in the wage distribution between rounds 4 and 5 . The average real wage went down slightly in Recession. Those wage cuts had a large effect on the distribution of effort choices in round 5, shown in the first row of CDFs. Although half of the workers in Inflation receive real wage cuts, the distribution of effort does not noticeably change.

\footnotetext{
${ }^{8}$ The standard deviation of the highest wage group is too large to show in Figure 4. The effort levels of the workers omitted from the graph are $0.05,0.25,0.6$, and 0.65 .
} 


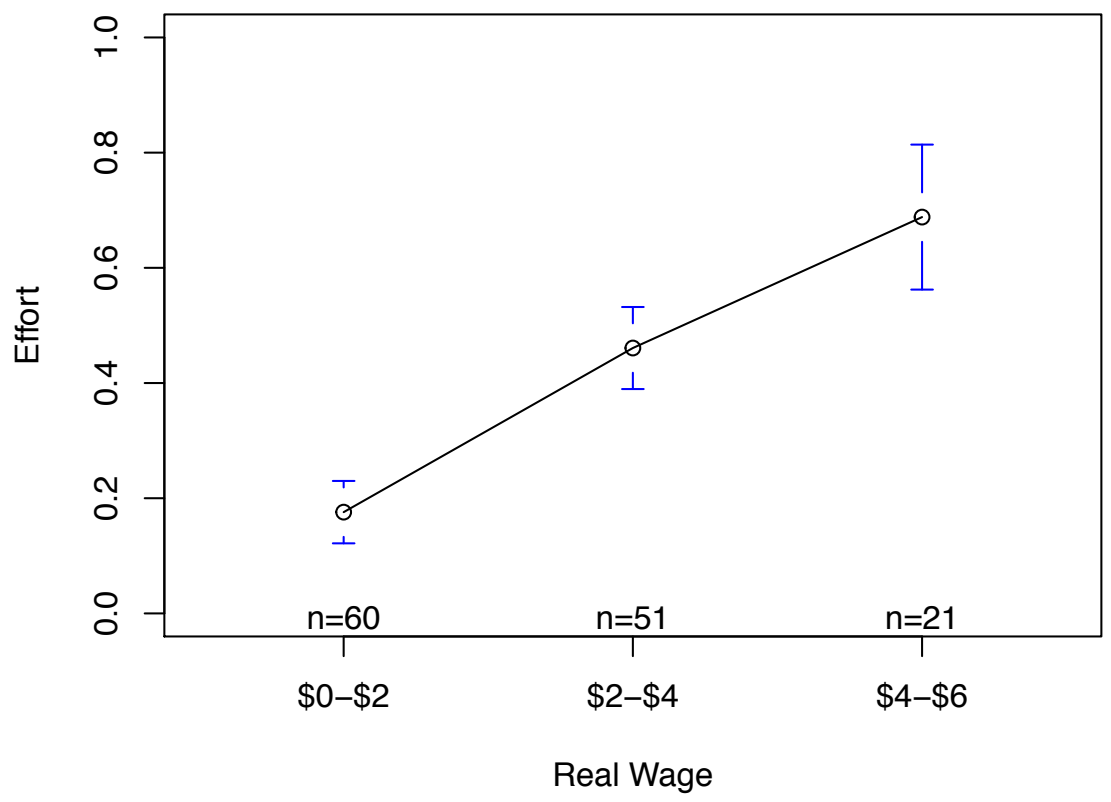

Figure 4: Effort in Round 4 by Real Wage

Figure 5 depicts the changes in the full sample between round 4 and 5 . The vertical line on the left of the effort graphs show that more than $20 \%$ of the workers pick an effort level of 0.05 in round 4 . The upward shift in the dashed line in the effort graph for Recession shows that the cumulative distribution of effort in Recession drops after half of the workers experience wage cuts. As we will show later, this is driven by the individuals who received wage cuts and who had previously been working above the minimum effort level.

Result 1: If a worker experiences a wage cut, they respond by reducing effort.

Because the effort choice is censored below at 0.05 , we use tobit analysis to measure the effect of a wage cut on effort between round 4 and 5 . We include a dummy for whether a worker experienced a real wage cut, in each treatment. We also include a dummy for round 5 to pick up a possible endgame effect that would cause effort for all the workers to fall. We indicate if a worker was at the minimum effort level in round 4 with MinimumEffort. A workers who is already at an effort level of 0.05 in round 4 cannot reduce their effort level any lower in response to a wage cut.

Column (3) of Table 1 shows tobit estimates for the following equation:

$e_{i t}=\beta_{2} I(\text { RealCut })_{i t} \times I(\text { Recession })_{i}+\beta_{0}+\beta_{1} I(\text { RealCut })_{i t} \times I(\text { Inflation })_{i}+\beta_{3} I(\text { Inflation })_{i}+\beta_{4} I(\text { Round } 5)_{t}+$ $\beta_{5}$ RealWage $_{i t}+\beta_{6} \log (\text { RealWage })_{i t}+\beta_{7} I($ MinimumEffort $)+\epsilon_{i t}$

If cooperation collapsed in the endgame, then the coefficient on Round 5 would be negative. It is clear from Table 1 and also Figure A1 that many workers reciprocate a high effort level if they feel they are being treated well, even though the employer has no means for punishment after round 4.

However, wage cuts lead to dramatic reductions in effort. With all of the controls in column (3), receiving a real wage cut in Recession is associated with a drop in effort by more than 0.15 which means more than 3 discrete intervals lower in the effort choices on average. The unlucky event of a recession does not appear 
Recession

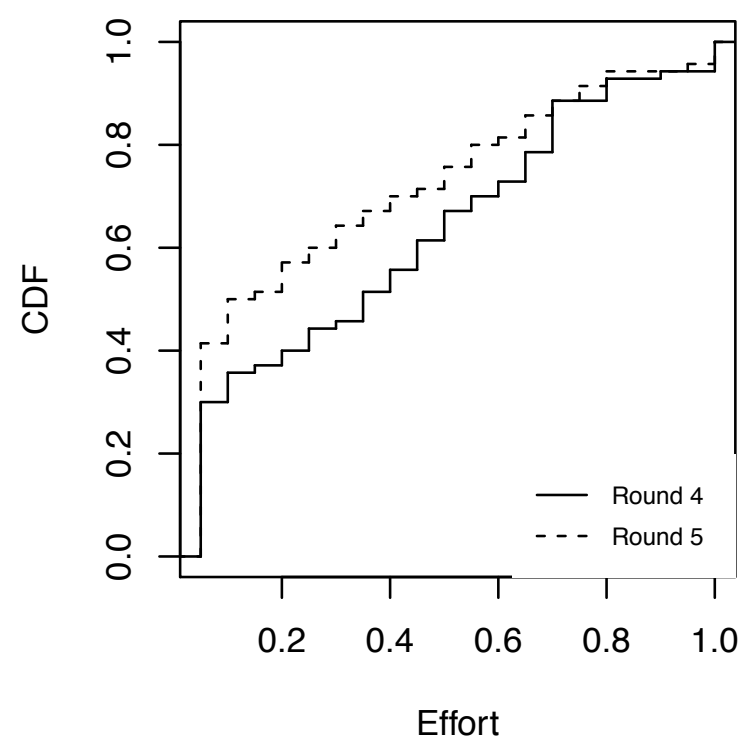

Recession

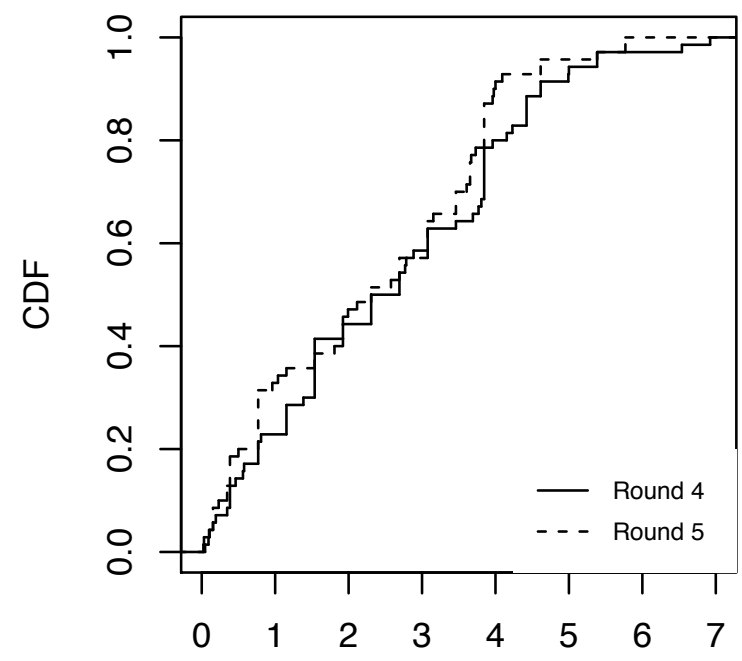

Real Wage
Inflation

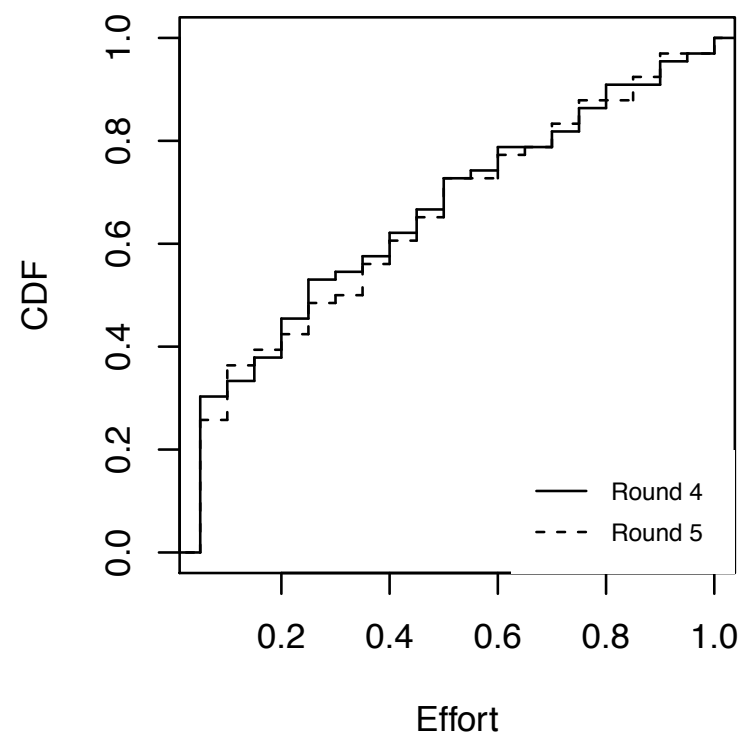

Inflation

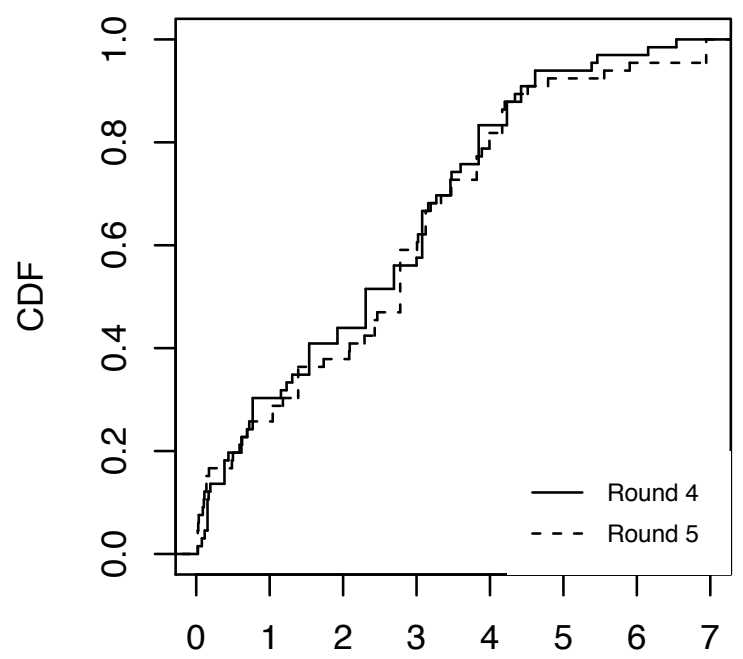

Real Wage

Figure 5: Cumulative Distribution of Effort and Real Wage in Rounds 4-5 by Treatment 
Table 1: Effort of Workers in Rounds 4-5, Tobit Analysis

\begin{tabular}{|c|c|c|c|}
\hline & \multicolumn{3}{|c|}{ Dependent variable: } \\
\hline & \multicolumn{3}{|c|}{ Effort } \\
\hline & $(1)$ & $(2)$ & $(3)$ \\
\hline Real Cut x Recession & $\begin{array}{c}-0.247^{* * *} \\
(0.093)\end{array}$ & $\begin{array}{c}-0.187^{* * *} \\
(0.072)\end{array}$ & $\begin{array}{c}-0.178^{* *} \\
(0.072)\end{array}$ \\
\hline Real Cut x Inflation & $\begin{array}{l}-0.154 \\
(0.098)\end{array}$ & $\begin{array}{l}-0.099 \\
(0.075)\end{array}$ & $\begin{array}{l}-0.103 \\
(0.076)\end{array}$ \\
\hline Inflation & $\begin{array}{l}-0.103 \\
(0.075)\end{array}$ & $\begin{array}{l}-0.063 \\
(0.054)\end{array}$ & $\begin{array}{l}-0.059 \\
(0.054)\end{array}$ \\
\hline Round 5 & $\begin{array}{c}0.059 \\
(0.065)\end{array}$ & $\begin{array}{c}0.046 \\
(0.049)\end{array}$ & $\begin{array}{c}0.042 \\
(0.049)\end{array}$ \\
\hline Real Wage & & $\begin{array}{c}0.093^{* * *} \\
(0.013)\end{array}$ & $\begin{array}{c}0.038 \\
(0.029)\end{array}$ \\
\hline $\log$ (Real Wage) & & & $\begin{array}{l}0.110^{* *} \\
(0.054)\end{array}$ \\
\hline Minimum Effort & & $\begin{array}{c}-0.584^{* * *} \\
(0.062)\end{array}$ & $\begin{array}{c}-0.544^{* * *} \\
(0.064)\end{array}$ \\
\hline Constant & $\begin{array}{c}0.274 \\
(0.308)\end{array}$ & $\begin{array}{c}0.091 \\
(0.224)\end{array}$ & $\begin{array}{c}0.172 \\
(0.224)\end{array}$ \\
\hline Session Fixed Effects & Yes & Yes & Yes \\
\hline Observations & 272 & 272 & 272 \\
\hline Log Likelihood & -165.599 & -59.048 & -56.696 \\
\hline
\end{tabular}

Note: The real wage cut dummy variables are "0" in round 4, and " 1 " in round 5 if the worker experienced a wage cut after round 4 . St. errors in parentheses. ${ }^{*} \mathrm{p}<0.1 ;{ }^{* *} \mathrm{p}<0.05 ;{ }^{* * *} \mathrm{p}<0.01$ 


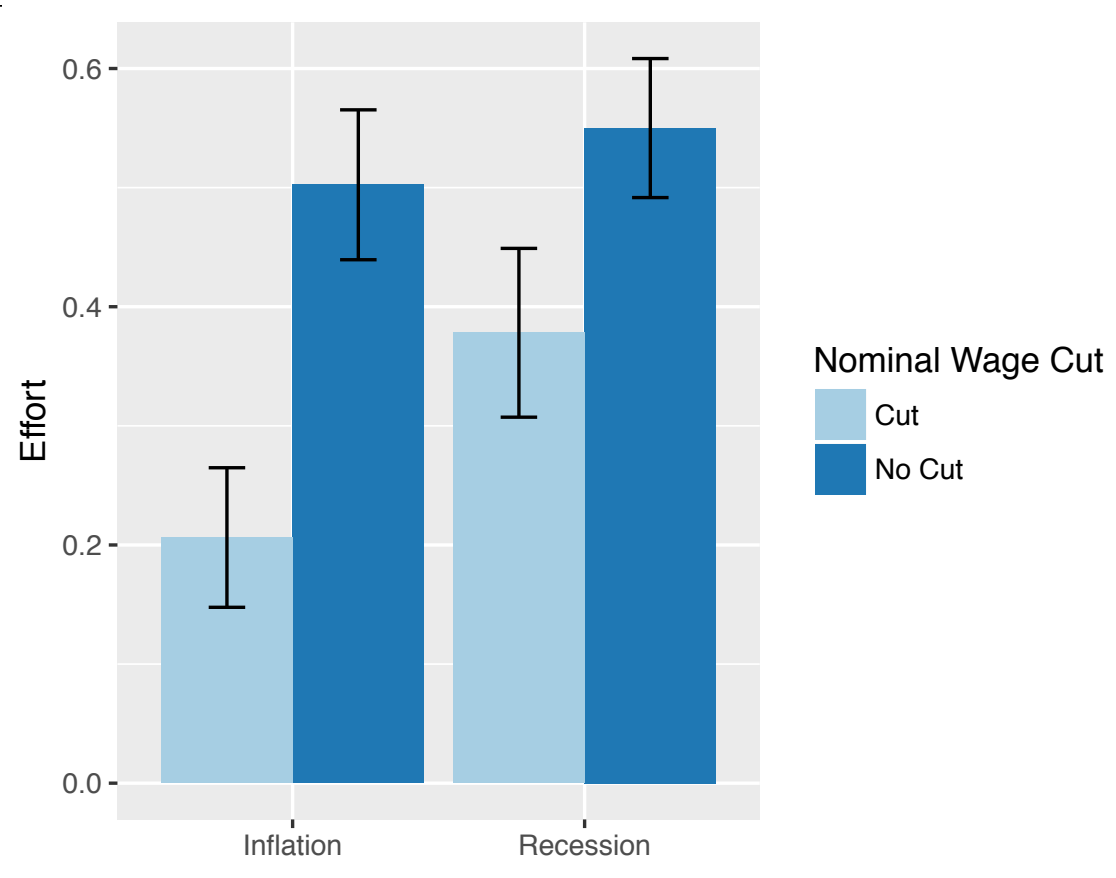

Figure 6: Comparing Effort after a Nominal Wage Cut, Columns show mean +/- S.E.M., Subjects with a real wage between $\$ 2-\$ 4$ in Round $5, \mathrm{n}=59$

to inspire sympathy toward employers. The size of the coefficient on wage cuts gets smaller when we control for the wage level, but it remains large and significant. The result is robust to using data from rounds 2-7 and also for adding a dummy variable indicating that a worker received a wage cut after round 1.

Judging by the magnitude of the coefficients on the cut dummies, real wage cuts matter more in Recession than in Inflation. The direction of the effect is negative for Inflation, but variance is higher, likely due to nominal illusion.

Figure 6 shows how workers who had somewhat good morale before the negative economic shock respond to nominal wage cuts. If a subject's real wage is between $\$ 2$ and $\$ 4$ in round 5 , and if that subject did not experience a nominal wage cut, then they will give back an effort level above 0.5 on average. Someone who experienced a wage in the same range but who got a nominal wage cut will work less. A nominal wage cut in Inflation implies a large real wage cut, so we observe a slightly larger response in Inflation. Here we exclude workers who were already at the minimum effort level in round 4, but the result is similar in the full sample, shown in A4. More detail on how effort changes in response to wage cuts in each treatment is documented in Appendix A.

This confirms the evidence we present in Table 1 . The wage in rounds 2-4 became a reference point and workers retaliated against wage cuts. Workers form a reference point after they are exposed to a fixed wage three times, from round 2 to round 4 . In our experiment, even after a recession, workers do not expect that the contract will be renegotiated. ${ }^{9}$

Result 2a: Despite the decline in effort in response to wage cuts, wage cuts are common.

Table 2 shows that nearly half of employers cut real wages between round 4 and round 5 . Nominal wage cuts occur nearly twice as often in Recession as in Inflation, which yields about the same number of real

\footnotetext{
${ }^{9}$ See Fehr et al. [2011] for an experimental test of how reference points are formed through contracting. In that study, buyers and sellers (sellers are our "employees") are randomly re-matched every round.
} 
Table 2: Wage Cut Behavior of Employers

\begin{tabular}{rcc}
\hline & Recession & Inflation \\
\hline Average Magnitude of Nominal Wage Cuts & -138 & -162 \\
\hline Number (\%) of Nominal Wage Cuts & $43(61 \%)$ & $25(38 \%)$ \\
\hline Average Magnitude of Real Wage Cuts & -1.06 & -1.03 \\
\hline Number (\%) of Real Wage Cuts & $43(61 \%)$ & $36(55 \%)$ \\
\hline
\end{tabular}

wage cuts in both treatments. The high frequency of nominal wage cuts in the experiment is surprising considering that wage cuts are rare in the economy. There are very few employers who hold nominal wages "rigid," even in Inflation. It is possible that some employers intend the wage cut to be a costly punishment, however the average effort level of workers who experienced a wage cut is not lower on average. ${ }^{10}$

Result 2b: Employers who cut nominal wages earn less in round 5.

The fact that so many employers choose to cut wages provides a unique opportunity to observe what happens to effort when wages fall. Because effort went down in response to wage cuts, the profits earned in round 5 by employers who cut nominal wages were lower than profits earned by employers who did not cut wages. In support of this hypothesis, we look at firms who were matched with a worker who was not shirking in Round 4 and we find that the profit of firms who implement nominal wage cuts is $29 \%$ lower than firms who did not ( $\$ 2.21$ vs. $\$ 3.09$; Wilcoxon rank-sum test, p-value $=0.01, n_{1}=48, n_{2}=47$ ). See additional results broken down by treatment in Table A1. A linear regression reported in Table A2 indicates that a nominal wage cut is associated with earning $\$ 0.70$ less in round 5 for all firms, controlling for treatment.

\subsection{Estimating Model Parameters for Effort and Beliefs}

After the wage and effort decisions are made in round 5 (and before employers learn the effort choice of the worker they are paired with), participants are asked to predict the effort choice of another participant who is in the room but with whom they have not interacted. They learn the wage and effort response in round 4 and the wage offer in round 5 for that worker. If they can correctly guess the worker's effort level in round 5 , they earn a bonus payment, so there is an incentive to be accurate.

Result 3: Employers do not anticipate how much effort falls after a nominal wage cut.

A nominal wage cut significantly reduces effort, as shown in the previous section. When predicting the actions of a worker in their experiment session, employers do not appear to understand the effect of wage cuts.

To compare the predicted and actual effect of nominal wage cuts, we estimate the parameter values of the model introduced in Section 2. Recall that $\alpha$ and $\beta$ measure positive reciprocity that leads to higher effort in response to higher wages. If workers react negatively to nominal wage cuts producing a discontinuity of the positive reciprocity function, then they have a positive value of $\lambda$.

The estimates presented in the first column of Table 3 are for the effort decisions in the actual data from

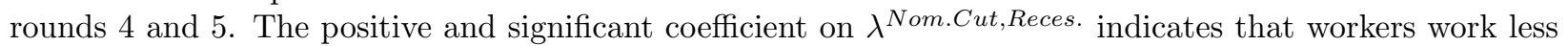
hard after receiving a nominal wage cut, when they are not distracted by inflation.

We obtain the coefficients with a nonlinear least squares estimation of the following equation:

$$
e_{i t}=\left(\frac{\alpha_{t}^{\text {Round } 4}+\alpha_{t}^{\text {Round } 5}}{1.2\left[1+\delta_{i t} \lambda^{\text {Nom.Cut }, \text { Reces. }}+\gamma_{i t} \lambda^{\text {Nom.Cut }, \text { Infl. }}\right]}\right)^{2} * w_{i t}^{2 \beta}
$$

\footnotetext{
${ }^{10}$ The average effort level in round 4 of workers who experience a real wage cut $(0.42)$ is higher than the average level of workers who do not experience a wage cut $(0.30)$.
} 
Table 3: Actual and Predicted Parameters of the Effort Function

\begin{tabular}{lcc}
\hline & Actual Effort, Rounds 4-5 & $\begin{array}{c}\text { Predictions by Employers } \\
\text { for Effort in Round 5 and } \\
\text { Actual Effort in Round } 4\end{array}$ \\
\hline$\beta$ & $0.202^{* * *}$ & $0.227^{* * *}$ \\
$(0.036)$ & $(0.037)$ \\
$\alpha^{\text {Round } 4}$ & $0.698^{* * *}$ & $0.678^{* * *}$ \\
& $(0.036)$ & $(0.034)$ \\
$\alpha^{\text {Round5 }}$ & $0.706^{* * *}$ & $0.657^{* * *}$ \\
& $(0.039)$ & $(0.038)$ \\
$\lambda^{\text {Nom.Cut,Reces. }}$ & $0.233^{* *}$ & 0.056 \\
& $(0.094)$ & $(0.067)$ \\
$\lambda^{\text {Nom.Cut,Infl. }}$ & $0.295^{*}$ & -0.018 \\
& $(0.151)$ & $(0.084)$ \\
\hline Observations & 190 & 190 \\
\hline \hline
\end{tabular}

Note: The table reports results of a nonlinear regression. Workers who provided effort of 0.05 in round 4 are excluded. The nominal wage cut dummy variables are "0" in Round 4, and "1" in round 5 if the worker experienced a wage cut after round 4 . Standard errors are in parentheses. ${ }^{*} \mathrm{p}<0.1 ;{ }^{* *} \mathrm{p}<0.05 ;{ }^{* * *} \mathrm{p}<0.01$ 
where $\delta$ is a dummy indicator for observations in the Recession treatment that involve a nominal wage cut. Let $\gamma$ be a dummy indicator for observations in the Inflation treatment that involve a nominal wage cut. The it subscript is added to these dummy indicators because they are person-specific and round-specific. Workers can only experience a wage cut in round 5 . Effort in round 4 and 5 is the variable on the left-hand side. The real wage offer to the worker is $w_{i t}$, which was observable to the worker deciding the actual effort and to the employer making the prediction. We estimate separate $\alpha$ coefficients for round 4 and round 5 so that we are able to capture an endgame effect.

To compare beliefs with actual effort decisions, we merge the effort choices from round 4 with the predictions made by employers. The estimate for the predicted $\lambda^{\text {Nom.Cut,Reces. }}$ in the second column of Table 3 is very small. Employers do not seem to realize how much wages cuts will upset workers. The sample in Table 3 excludes 41 workers who chose effort of 0.05 in round 4 . Results for the full sample are reported in Table A3.

Using the model described in Section 2 and the parameters used in the experiment, we can calculate a threshold level of $\lambda$ above which wage rigidity is a more profitable strategy for firms during a recession (see Appendix B for derivation). The value 0.233 estimated for the actual effort decisions without inflation is well above that threshold level. For most employers, keeping wages rigid would have been a more profitable strategy in this experiment.

Note that subjects enter the lab together and complete identical instructions before being informed of their randomly assigned role in the experiment. Although they have access to all of the same information that workers had, employers have a poor understanding of the reciprocity dynamics, as indicated not just by their wage choice but by their predictions of worker behavior. This information about the beliefs of employers helps eliminate the competing explanation that employers lowered wages out of spite knowing that they would lose money.

Different environments could put workers out of "system 1" (the unreflective reaction mode of action described by Kahneman [2011]) and cause them to behave more like the employers predicted they would. For example, Gerhards and Heinz [2017] in a different experiment did not find that employees retaliated against wage cuts. Also, it is a question for future research whether and how employers would learn. Sliwka and Werner [2017] similarly found that experimental subjects in the role of employers made suboptimal choices, likely because they did not understand how to motivate workers. However, professional human resource managers were capable of predicting how workers would respond to different wage profiles in that experiment.

\subsection{Loss Aversion}

After our experiment, subjects answer several questions. We elicit loss aversion using a menu of 6 lottery choices. Every lottery offers a $50 \%$ chance to win $\$ 7$. The equally-probably loss is $\$ 3$ in the first lottery and increases by $\$ 1$ for each subsequent lottery (modifying Gächter et al. [2007]). A highly loss averse subject might decline a chance to play any of these lotteries. Our measure of loss tolerance is the total number of lotteries chosen by the individual. After every subject submitted their choices, one subject volunteered to roll a die and flip a coin. The die determined the lottery that would be paid and the coin flip determined whether the subjects who agreed to play that lottery would win $\$ 7$ or lose money out of their earnings in the experiment. Women exhibit more loss aversion than men; however, gender does not significantly influence wage or effort choices.

The first result from examining the effect of loss aversion is that loss averse employers are less likely to cut nominal wages in Recession. Figure 7 presents results for employers labeled Loss Averse and Loss Tolerant based on their choices in the loss aversion elicitation. A Loss Averse subjects is one who reject all lotteries or who only accepted one lottery. Among Loss Averse employers, there are as many employers who decided not to cut nominal wages after the shock in Recession as those who did cut wages. The pattern among Loss Tolerant employers appears different. Loss Tolerant employers are more likely to cut wages, which they might have thought was fair given the negative economic shock.

The apparent pattern in Figure 7 is not significant with a chi-square test for the full sample. However, if we apply our usual restriction of only looking at firms who are paired with a worker that was not already 


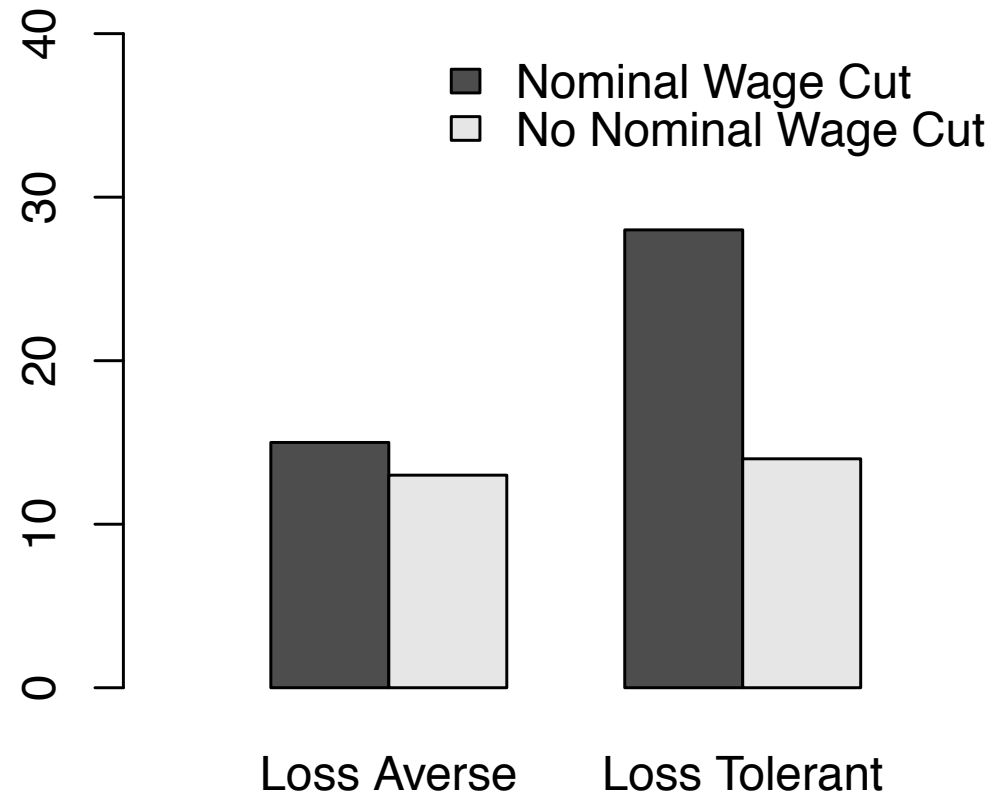

Figure 7: Instances of Nominal Wage Cuts by Loss Averse Employers in Recession, $\mathrm{n}=70$ 
at the minimum effort level in round 4, then the chi-squared test is significant at the $10 \%$ level. There is no similar effect in Inflation, which might be because employers can give a real wage cut without altering the nominal wage.

The different behavior of loss averse employers suggests that they hold different beliefs about how workers react to wage cuts. There is suggestive evidence from the nonlinear model estimating $\lambda$ from the previous section that loss averse employers in Recession have different beliefs that loss tolerant employers in Recession, but the difference is not statistically significant. That would be a promising area for future study.

Also using a version of the model reported in Table 3, we can test if workers who are more loss averse also react more strongly to wage cuts. It is not the case that workers who appear loss averse in the loss aversion elicitation react more strongly to wage cuts. We do not take this as evidence that loss aversion is unrelated to effort provision. Abeler et al. [2011] found that loss aversion, as measured by similar lottery choices, predicted a subject's decision to stop working early at tedious tasks to avoid a loss.

Reference-dependent taxi drivers in New York stop working once they have achieved a daily income target (Crawford and Meng [2011]), and in a field experiment, Fehr and Goette [2007] also find that loss aversion correlates with the decision of bicycle messengers to stop working early to avoid loss. Similarly Abeler et al. [2011] show that experimental subjects will stop working early at a real effort task in order avoid a loss relative to an induced reference point. Subjects in the Abeler et al. study have a $50 \%$ chance of winning a fixed payment $f$ and often complete just enough tasks so that $50 \%$ of the time they would also obtain $f$ from their piece-rate earnings. Subjects considered loss averse (because they decline lotteries with a positive expected value to avoid possible losses) are more likely to stop working at the point that minimizes the potential for disappointment.

In our experiment, workers cannot explicitly avoid losses, so perhaps experiments in which people give up money to avoid losses cannot always be used to predict behavior when people are reacting to a loss that has been forced on them. We find that whether or not a worker is loss aversion by standard measures, they will punish a wage cut with a reduction in effort.

\section{Conclusion}

Since wage cuts are rare in the economy and the output of individual workers is often unobservable, our experiment provides a unique opportunity to test the morale theory of wage rigidity. We find that workers reduce effort in reaction to nominal wage cuts. Although this fall in morale is often used as an explanation for wage rigidity, half of the employers in our experiment cut wages. The reason, as least in part, is that firms have incorrect beliefs about how workers will react to wage cuts. We are the first to make an explicit link between beliefs and the behavior of employers.

Our experiment highlights the role of beliefs in economy-wide wage rigidity. We have not ruled out other reasons for wage rigidity, such as menu costs and peer comparison. However, we show that a manager with correct beliefs should probably avoid cutting wages, even in the absence of those forces, and in our environment managers who do not cut wages earn more money.

There is a growing literature indicating that labor supply is affected by loss aversion. Workers in our experiment are reacting to a loss instead of avoiding a loss. Our results lead to questions for future research. Do the same people who would pay to avoid a loss also react the most strongly to losses they cannot avoid? We also present a good method for examining the effects of inflation on decision making which can be used in future research.

Economists cannot precisely define the circumstances under which workers perceive nominal wage cuts as offensive. Bracha et al. [2015] found that effort provision is affected by jealousy of a peer earning a higher wage. However, if a sufficient justification is given for unequal pay, the difference in effort provision disappears. Friedman [1968] argued that the effects of inflation diminish as people realized through experience what the real variables are. Negative reciprocity is contingent on the larger context of a decision (Cox and Deck [2005]). In what context would employers accurately perceive the insult caused by a wage cut (see Kendall and Oprea [2018] on belief correction)? Future experiments could discover which contexts induce workers to act according to the predictions of our naïve employers. 
In conclusion, we present an experiment designed test behaviors that have important macroeconomic implications. Taylor [1980] proposed that price rigidity is partly due to staggered nominal contracts. It is costly to renegotiate a contract, so for an individual firm in any given period it is often rational to remain in a sub-optimal price contract. Calvo [1983] presents a highly tractable and widely-used model wherein only a certain fraction of firms are able to adjust prices in each period of time. Little work has been done that would allow economists to predict which firms adjust prices. Future research can establish how firms form their beliefs and how the feedback from the behavior of workers leads to wage rigidity among a large fraction of firms in most countries.

Acknowledgements: We thank seminar participants at Chapman University, the Workshop on Experimental Macroeconomics, and the Economic Science Association meetings. Our paper was improved by conversations with Misha Freer, Steven Gjerstad, Cesar Martinelli, Ryan Oprea, and Arno Riedl, and by comments from anonymous referees. Funding was provided by the National Science Foundation SES 1628911.

\section{References}

J. Abeler, A. Falk, L. Goette, and D. Huffman. Reference points and effort provision. The American Economic Review, 101(2):470-492, 2011.

G. A. Akerlof, W. T. Dickens, G. L. Perry, R. J. Gordon, and N. G. Mankiw. The macroeconomics of low inflation. Brookings papers on economic activity, 1996(1):1-76, 1996.

T. F. Bewley. Why wages don't fall during a recession. Harvard University Press, 1999.

A. Bracha, U. Gneezy, and G. Loewenstein. Relative pay and labor supply. Journal of Labor Economics, 33 (2):297-315, 2015.

J. Brandts and G. Charness. Do labour market conditions affect gift exchange? Some experimental evidence. The Economic Journal, 114(497):684-708, 2004.

M. Brown, A. Falk, and E. Fehr. Competition and relational contracts: the role of unemployment as a disciplinary device. Journal of the European Economic Association, 10(4):887-907, 2012.

G. A. Calvo. Staggered prices in a utility-maximizing framework. Journal of Monetary Economics, 12(3): 383-398, 1983.

C. M. Campbell and K. S. Kamlani. The reasons for wage rigidity: evidence from a survey of firms. The Quarterly Journal of Economics, 112(3):759-789, 1997.

G. Charness. Attribution and Reciprocity in an Experimental Labor Market. Journal of Labor Economics, 22(3):665-688, 2004. ISSN 0734-306X. doi: 10.1086/383111.

D. L. Chen and J. J. Horton. Research NoteAre Online Labor Markets Spot Markets for Tasks? A Field Experiment on the Behavioral Response to Wage Cuts. Information Systems Research, 27(2):403-423, 2016.

J. C. Cox and C. A. Deck. On the nature of reciprocal motives. Economic Inquiry, 43(3):623-635, 2005.

J. C. Cox, D. Friedman, and S. Gjerstad. A tractable model of reciprocity and fairness. Games and Economic Behavior, 59(1):17-45, Apr. 2007. ISSN 0899-8256. doi: 10.1016/j.geb.2006.05.001.

V. P. Crawford and J. Meng. New york city cab drivers' labor supply revisited: Reference-dependent preferences with rational expectations targets for hours and income. The American Economic Review, 101 (5):1912-1932, 2011. 
M. C. Daly and B. Hobijn. Downward Nominal Wage Rigidities Bend the Phillips Curve. Journal of Money, Credit and Banking, 46(S2):51-93, Oct. 2014. ISSN 1538-4616. doi: 10.1111/jmcb.12152.

S. DellaVigna, J. A. List, U. Malmendier, and G. Rao. Estimating social preferences and gift exchange at work. Technical report, National Bureau of Economic Research, 2016.

S. DellaVigna, A. Lindner, B. Reizer, and J. F. Schmieder. Reference-dependent job search: evidence from hungary. The Quarterly Journal of Economics, 132(4):1969-2018, 2017.

W. T. Dickens, L. Goette, E. L. Groshen, S. Holden, J. Messina, M. E. Schweitzer, J. Turunen, and M. E. Ward. How Wages Change: Micro Evidence from the International Wage Flexibility Project. The Journal of Economic Perspectives, 21(2):195-214, Apr. 2007.

P. Diriwächter and E. Shvartsman. The anticipation and adaptation effects of intra-and interpersonal wage changes on job satisfaction. Journal of Economic Behavior \& Organization, 146:116-140, 2018.

P. Doerrenberg, D. Duncan, and M. Löffler. Asymmetric labor-supply responses to wage-rate changesevidence from a field experiment. ZEW-Centre for European Economic Research Discussion Paper, (16-006), 2016.

N. Erkal, L. Gangadharan, and B. H. Koh. Monetary and non-monetary incentives in real-effort tournaments. European Economic Review, 101(Supplement C):528 - 545, 2018. ISSN 0014-2921. doi: https://doi.org/ 10.1016/j.euroecorev.2017.10.021.

E. Fehr and L. Goette. Do workers work more if wages are high? Evidence from a randomized field experiment. The American Economic Review, 97(1):298-317, 2007.

E. Fehr, G. Kirchsteiger, and A. Riedl. Does Fairness Prevent Market Clearing? An Experimental Investigation. The Quarterly Journal of Economics, 108(2):437-459, 1993. ISSN 0033-5533. doi: 10.2307/2118338.

E. Fehr, O. Hart, and C. A. Zehndera. Contracts as reference points experimental evidence. The American Economic Review, 101(2):493-525, 2011.

U. Fischbacher. z-Tree: Zurich toolbox for ready-made economic experiments. Experimental Economics, 10 (2):171-178, 2007.

M. Friedman. The role of monetary policy. American Economic Review, 58(1), 1968.

S. Gächter and C. Thoni. Social comparison and performance: Experimental evidence on the fair wageeffort hypothesis. Journal of Economic Behavior \& Organization, 76(3):531-543, Dec. 2010. ISSN 0167-2681. doi: $10.1016 /$ j.jebo.2010.08.008.

S. Gächter, E. J. Johnson, and A. Herrmann. Individual-Level Loss Aversion in Riskless and Risky Choices. Institute for the Study of Labor, (IZA DP No. 2961):25, 2007.

L. Gerhards and M. Heinz. In good times and bad reciprocal behavior at the workplace in times of economic crises. Journal of Economic Behavior \& Organization, 134:228-239, 2017.

R. L. Hannan, J. H. Kagel, and D. V. Moser. Partial gift exchange in an experimental labor market: Impact of subject population differences, productivity differences, and effort requests on behavior. Journal of Labor Economics, 20(4):923-951, 2002.

D. Kahneman. Thinking, fast and slow. Macmillan, 2011.

C. Kendall and R. Oprea. Are biased beliefs fit to survive? an experimental test of the market selection hypothesis. Journal of Economic Theory, 176:342-371, 2018. 
B. Köszegi and M. Rabin. A model of reference-dependent preferences. The Quarterly Journal of Economics, 121(4):1133-1165, 2006.

S. Kube, M. A. Marchal, and C. Puppe. Do wage cuts damage work morale? Evidence from a natural field experiment. Journal of the European Economic Association, 11(4):853-870, 2013.

S. Linardi and C. Camerer. Can relational contracts survive stochastic interruptions? experimental evidence. Working Paper. University of Pittsburgh., 2012.

C. N. Noussair, G. Richter, and J.-R. Tyran. Money illusion and nominal inertia in experimental asset markets. Journal of Behavioral Finance, 13(1):27-37, 2012.

S. Schmitt-Grohé and M. Uribe. Downward nominal wage rigidity, currency pegs, and involuntary unemployment. Journal of Political Economy, 124(5):1466-1514, 2016.

D. Sliwka and P. Werner. Wage Increases and the Dynamics of Reciprocity. Journal of Labor Economics, 35(2):299-344, 2017.

J. B. Taylor. Aggregate dynamics and staggered contracts. Journal of political economy, 88(1):1-23, 1980. 


\section{A.1 Analysis of Worker Effort}
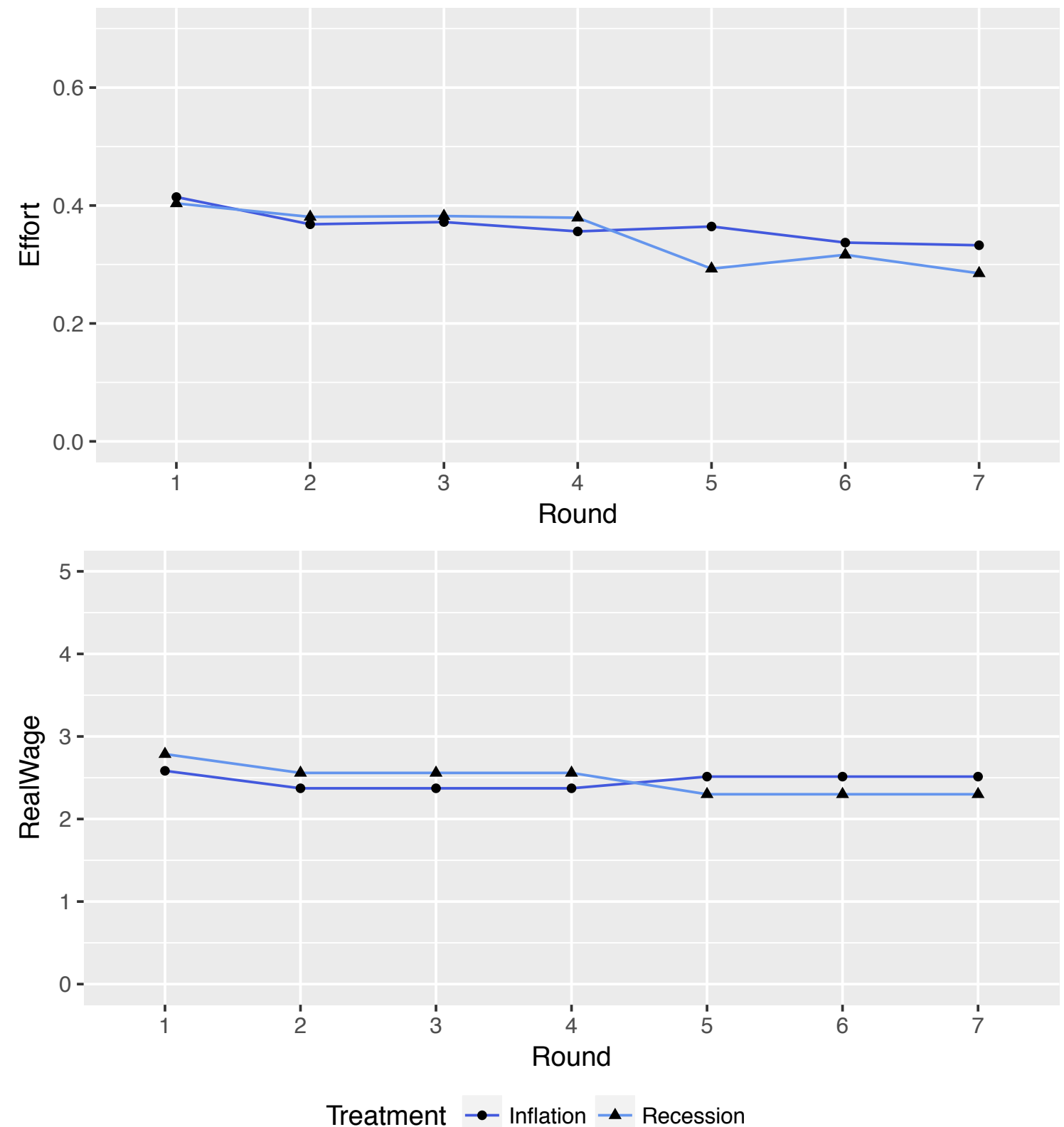

Figure A1: Average Effort over 7 Rounds, Full Sample

Figure 6 indicates that effort is significantly lower from workers who received a wage cut. It is important to establish the fact that effort changed relative to what individual workers were doing in round 4 , not that workers who were already at a low level of effort were the ones to receive wage cuts.

The full sample of workers is shown in Figure A2. Workers who received a wage cut decreased their effort in percentage terms. It is misleading to make treatment comparisons without also taking the percentage 


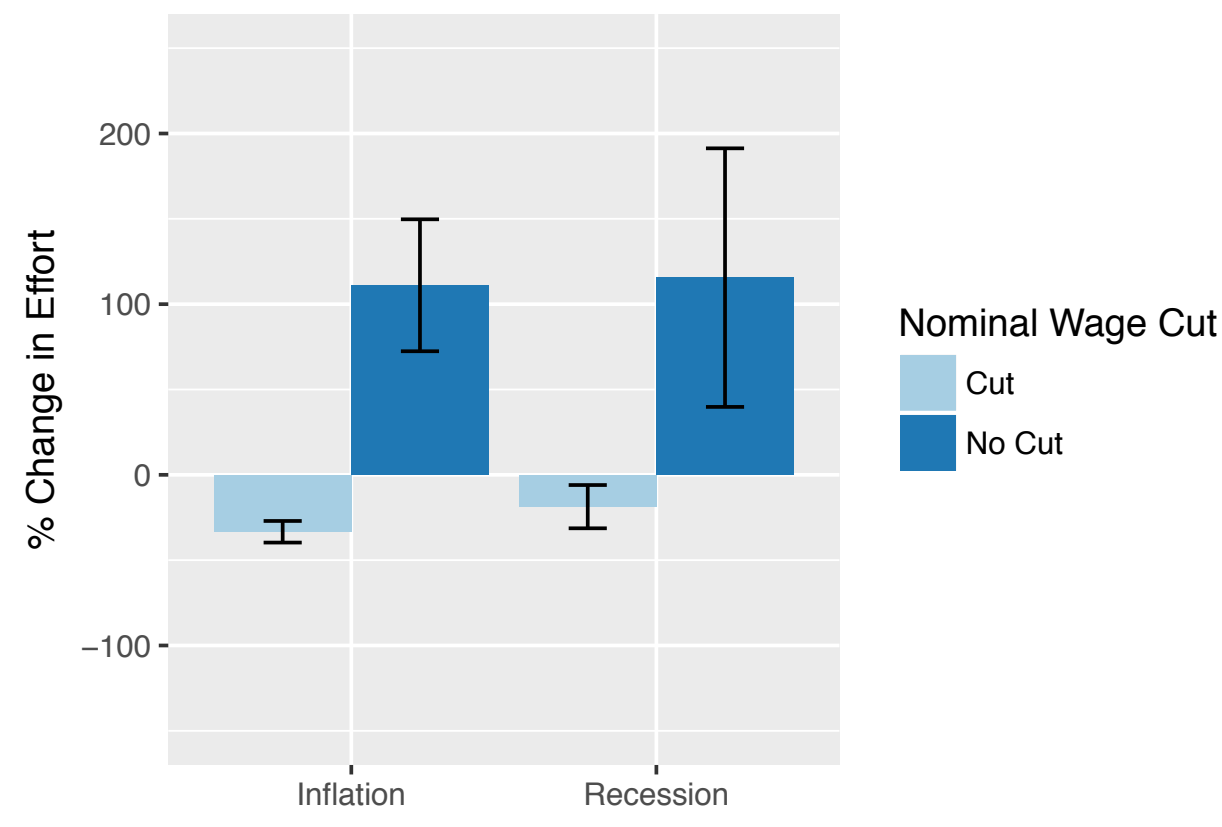

Figure A2: Percent Change in Effort from Round 4 to Round 5, Full Sample

change of the wage into account. Among workers who received a wage cut, the magnitude of the percent change in wage was largest in Inflation.

In Figure A2, the extreme upswing in effort among workers who did not receive a nominal wage cut is driven by several workers who were at the minimum effort level in round 4. Most of them remained at the minimum in round 5 (they cannot go down any further in response to a wage cut). However, some of those workers increased their effort which produced a change of up to $1400 \%$. (Moving from 0.5 to 1 is an increase of $100 \%$ while moving the other way from 1 to 0.5 is a decrease of $50 \%$. )

The sample used in Figure 6 is preferable to convey what the cooperative subjects did in the experiment and how they responded to wage changes. Figure A3 pictures the average effort changes among subjects who had the option of lowering their effort level because they were above 0.05 in round 4 . When workers at the minimum effort level are removed, 95 observations of workers remain. The relevant economic question addressed in this paper is how to maintain good worker morale, which assumes that good morale exists before a negative economic shock.

Figure A3 indicates that workers who experienced a wage cut reduced their effort significantly, relative to their effort level in round 4. 


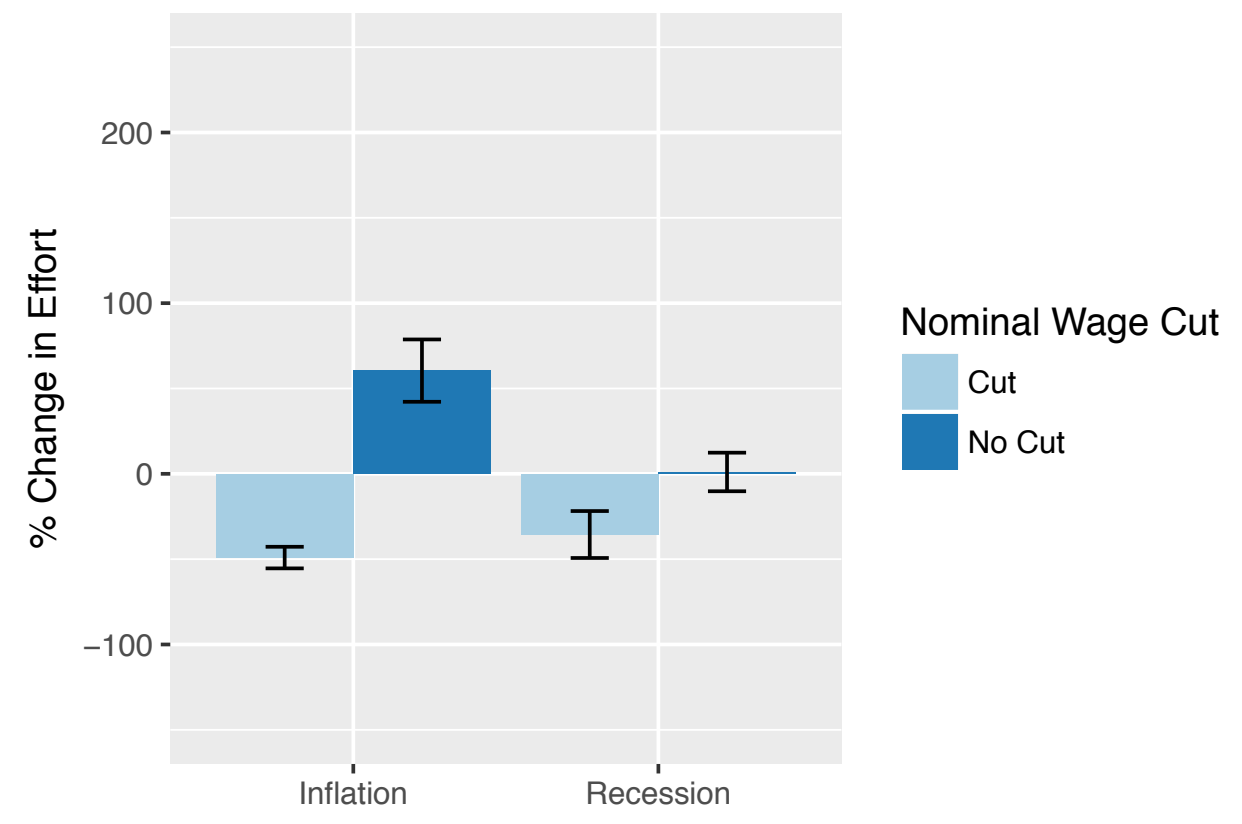

Figure A3: Percent Change in Effort from Round 4 to Round 5, $e_{4}>0.05$ Workers

\section{A.2 Analysis of Full Sample of Subjects}

Table A1: Profit of Firms in Round 5 Paired with Workers Who Were Above the Minimum Effort Level in Round 4, Wilcoxon Mann-Whitney test

\begin{tabular}{cccc}
\hline Recession & $\mathrm{n}$ & Median & $\mathrm{p}$-value \\
\cline { 1 - 3 } No Nominal Wage Cut in Round 5 & 18 & $\$ 2.88$ & \multirow{2}{*}{0.12} \\
\cline { 1 - 3 } Nominal Wage Cut in Round 5 & 43 & $\$ 2.15$ & \\
\cline { 1 - 2 } Inflation & & & \\
\cline { 1 - 2 } No Nominal Wage Cut in Round 5 & 29 & $\$ 3.22$ & \multirow{2}{*}{0.04} \\
\cline { 1 - 2 } Nominal Wage Cut in Round 5 & 17 & $\$ 2.28$ & \\
\hline
\end{tabular}


Table A2: Effect of Nominal Wage Cut in Round 5 on Employer Profits, Linear Regression

\begin{tabular}{|c|c|c|}
\hline & \multicolumn{2}{|c|}{ Dependent variable: } \\
\hline & \multicolumn{2}{|c|}{ Profit } \\
\hline & (1) & $(2)$ \\
\hline Nominal Wage Cut & $\begin{array}{c}-0.617^{* *} \\
(0.269)\end{array}$ & $\begin{array}{c}-0.772^{* *} \\
(0.348)\end{array}$ \\
\hline Inflation & & $\begin{array}{l}-0.197 \\
(0.351)\end{array}$ \\
\hline Nominal Wage Cut x Inflation & & $\begin{array}{c}0.232 \\
(0.500)\end{array}$ \\
\hline Minimum Effort Round 4 & & $\begin{array}{c}-1.535^{* * *} \\
(0.265)\end{array}$ \\
\hline Constant & $\begin{array}{c}2.348^{* * *} \\
(0.190)\end{array}$ & $\begin{array}{c}2.940^{* * *} \\
(0.286)\end{array}$ \\
\hline Observations & 136 & 136 \\
\hline $\mathrm{R}^{2}$ & 0.038 & 0.235 \\
\hline Adjusted $\mathrm{R}^{2}$ & 0.031 & 0.212 \\
\hline Residual Std. Error & $1.570(\mathrm{df}=134)$ & $1.416(\mathrm{df}=131)$ \\
\hline F Statistic & $5.257^{* *}(\mathrm{df}=1 ; 134)$ & $10.055^{* * *}(\mathrm{df}=4 ; 131)$ \\
\hline
\end{tabular}

Note: The control in column (2) is a dummy for whether the firm is paired with a worker who was at the minimum effort level of 0.05 in round 4 and therefore could not reduce effort in response to a wage cut. ${ }^{*} \mathrm{p}<0.1 ;{ }^{* *} \mathrm{p}<0.05 ;{ }^{* * *} \mathrm{p}<0.01$ 


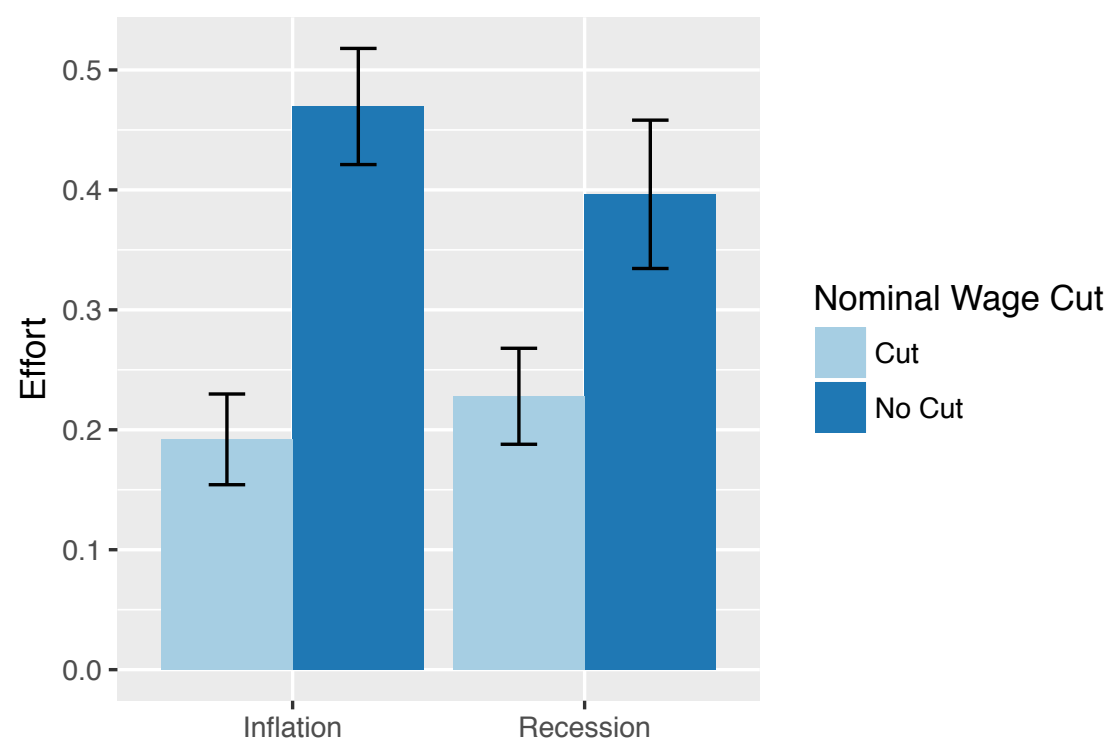

Figure A4: Comparing Effort after a Nominal Wage Cut, Columns show mean +/- S.E.M., n=136

Table A3: Actual and Predicted Parameters of the Effort Function, Full Sample

Actual Effort, Rounds 4-5 Predictions by Employers for Effort in Round 5 and Actual Effort in Round 4

\begin{tabular}{lcc}
\hline$\beta$ & $0.256^{* * *}$ & $0.259^{* * *}$ \\
& $(0.037)$ & $(0.035)$ \\
$\alpha^{\text {Round } 4}$ & $0.607^{* * *}$ & $0.605^{* * *}$ \\
& $(0.031)$ & $(0.029)$ \\
$\alpha^{\text {Round5 }}$ & $0.603^{* * *}$ & $0.604^{* * *}$ \\
& $(0.036)$ & $(0.034)$ \\
$\lambda^{\text {Nom.Cut,Reces. }}$ & 0.140 & 0.001 \\
& $(0.093)$ & $(0.066)$ \\
$\lambda^{\text {Nom.Cut,Infl. }}$ & 0.197 & -0.010 \\
& $(0.150)$ & $(0.088)$ \\
\hline Observations & 272 & 272 \\
\hline \hline
\end{tabular}

${ }^{1}$ The table reports results of a nonlinear regression. The nominal wage cut dummy variables are " 0 " in Round 4, and " 1 " in round 5 if the worker experienced a wage cut after round 4 . Standard errors are in parentheses. ${ }^{*} \mathrm{p}<0.1 ;{ }^{* *} \mathrm{p}<0.05 ;{ }^{* * *} \mathrm{p}<0.01$ 


\section{B Closed Form Estimates}

\section{B.1 Best-Response Function for a Worker}

This is the derivation of the utility maximizing effort choice by a worker who reciprocates high effort for high wages if $\alpha>0$. Recall the utility function:

$$
U_{t}=w_{t}-c\left(e_{t}\right)+\frac{\alpha}{1+\lambda_{t}} * w_{t}^{\beta} * e_{t}
$$

Obtain the first order condition by setting the derivative $\delta U / \delta e=0$.

$$
w_{t}^{\beta}=1.2 e_{t}^{.5}
$$

Simply solve for effort to obtain the best-response to the wage.

\section{B.2 Optimal Wage for a Profit-Maximizing Employer}

This is the derivation of the optimal nominal wage without loss aversion, assuming an interior solution. The real profit can be found by dividing the nominal profit by the price level.

$$
\pi=(R-n) * e
$$

First, we substitute effort with the best response function of the worker.

$$
\pi=(R-n) * \frac{\alpha^{2}}{1.44} * n^{2 \beta}
$$

We arrive at a first order condition by taking the derivative.

$$
\frac{\delta \pi}{\delta n}=(R-n)\left[2 \beta n^{2 \beta-1}\right]-n^{2 \beta}=0
$$

Rearranging, we simplify to $R-n=\frac{n}{2 \beta}$.

$$
n^{*}=\frac{\beta R}{\beta+1 / 2}
$$

\section{B.3 Derive Threshold level of Loss Aversion for Wage Rigidity to be Optimal Wage-Setting Strategy}

The profit-maximizing condition is $\left(R_{1}-n_{0}\right) \hat{e}\left(n_{0}, \lambda_{I}\right)>\left(R_{1}-n_{1}\right) \hat{e}\left(n_{1}, \lambda_{I}\right)$.

The threshold value is a function of the specific parameters, so the first step is to insert the parameters we use in our experiment: $R_{0}=1150 ; R_{1}=1035 ; \alpha=0.3 ; \beta=0.2$.

Next, we substitute the effort response, $\hat{e}\left(w_{1}, \lambda_{I}\right)=\left(\frac{\alpha}{1.2\left(1+\lambda_{I}\right)}\right)^{2} * w_{1}{ }^{2 \beta}$. The level of $\lambda$ that satisfies this equality is the lowest level that could cause wage rigidity to be a profit-maximizing strategy on the part of strategic employers. By rearranging the equation and solving for $\lambda_{I}$, we find this lower bound, $\underline{\lambda}>0.002$. The lower bound is small, thus it does not take a large degree of loss aversion for wage rigidity to result, in our stylized example. After the drop in $R$, the new $n^{*}$ falls as defined in the section above, but if $\lambda$ is sufficiently large, the more profitable strategy is for firms to remain at the previous wage level. 


\section{$\mathrm{C}$ Text of the Instructions}

Welcome. You have the opportunity to earn cash at the end of this experiment based on the decisions made by you and others. At the end of the experiment and after a questionnaire, you will be paid the total amount you have earned in the experiment plus $\$ 5$ for arriving on time today.

Out of several participants, half of you are randomly selected to be employers and half of you are employees. No one will know your identity or the actions you take during this experiment.

At any time during the instructions, raise your hand and the experimenter will answer questions. Please turn off all electronic devices. Talking or communication is not allowed during the experiment.

To calculate how much money you can earn, you will use addition and multiplication. The first computer screen is to practice calculation and opening the calculator tool. Click Begin on the screen to start the math practice. Click on the calculator icon to open the calculator tool.

Add the following numbers together. $12.34+56$

Multiply these two numbers. $\quad 45 \times 9.01$

Type your answers into the boxes on the screen. Click Submit Calculations to continue. This is a timeline for the experiment. There are 7 rounds. In every round, there are 3 steps. Some questions will be asked after Round 5 and after Round 7.

\begin{tabular}{|cl|l|}
\hline Stage 0 & Round 1 & $\begin{array}{l}\text { Step 1 } \\
\text { Step 2 } \\
\text { Step 3 }\end{array}$ \\
\hline Stage 1 & Round 2 & Steps... \\
& $\begin{array}{c}\text { Round 3 } \\
\text { Round 4 }\end{array}$ & \\
\hline Stage 2 & Round 5 & Questions \\
& Round 6 & \\
& Round 7 & \\
\hline Questionnaire & & \\
\hline
\end{tabular}

If you are an employee you will be matched with one of the employers for all rounds. Each repeated round will consist of the following steps, although some rounds do not include step 1.

\section{Step 1:}

An employer sets a salary that they will pay (this will not happen in Round 3, 4, 6, or 7). The salary number is in Experiment Currency Units (ECUs), the tickets that you earn during the experiment. The employer cannot set a wage that is so high that the employer will lose money or that is so low that the employee will lose money.

The employer sets a salary or wage in Round 1. They can change that wage or keep the same wage for Round 2. The wage will stay the same for rounds 2, 3 and 4. Employers may change the wage between Round 4 and Round 5, or they may keep the wage the same. The wage in Round 5, 6, and 7 will be the same.

\begin{tabular}{|cl|l|}
\hline Stage 0 at wage $_{0}$ & Round 1 & $\begin{array}{l}\text { Step 1: Set first wage level for Round 1 } \\
\text { Step 2: Set first effort level } \\
\text { Step 3: Review payments }\end{array}$ \\
\hline Stage 1 at wage $_{1}$ & $\begin{array}{l}\text { Round 2 } \\
\text { Round 3 } \\
\text { Round 4 }\end{array}$ & Set a wage for Rounds 2-4 \\
\hline Stage 2 at wage $_{2}$ & $\begin{array}{l}\text { Round 5 } \\
\text { Round 6 } \\
\text { Round 7 }\end{array}$ & \\
\hline Questionnaire & & \\
\hline
\end{tabular}




\section{Step 2:}

The employee observes the wage and chooses his or her effort level. The possible effort choices are shown in this table:

\begin{tabular}{|l|l|l|l|l|l|l|l|l|l|l|l|l|l|l|l|l|l|l|l|}
\hline .05 & 0.1 & .15 & 0.2 & .25 & 0.3 & .35 & 0.4 & .45 & 0.5 & .55 & 0.6 & .65 & 0.7 & .75 & 0.8 & .85 & 0.9 & .95 & 1 \\
\hline
\end{tabular}

Participants review the results from the round. Results are displayed in Experiment Currency Units (ECUs) they earned during the round. ECUs will be exchanged for dollars in cash at the end according to an exchange rate.

How to Earn Money

An employee earns a wage from the employer. The employee pays the cost of the effort level that he or she chooses. Practice reading the cost of effort table (split into two tables).

\begin{tabular}{|c|c|c|c|c|c|c|c|c|c|c|}
\hline Effort & 0.05 & 0.1 & 0.15 & 0.2 & 0.25 & 0.3 & 0.35 & 0.4 & 0.45 & 0.5 \\
\hline Cost & $\$ 0.01$ & $\$ 0.03$ & $\$ 0.05$ & $\$ 0.07$ & $\$ 0.10$ & $\$ 0.13$ & $\$ 0.17$ & $\$ 0.2$ & $\$ 0.24$ & $\$ 0.28$ \\
\hline Effort & 0.55 & 0.6 & 0.65 & 0.7 & 0.75 & 0.8 & 0.85 & 0.9 & 0.95 & 1 \\
\hline Cost & $\$ 0.33$ & $\$ 0.37$ & $\$ 0.42$ & $\$ 0.47$ & $\$ 0.52$ & $\$ 0.57$ & $\$ 0.63$ & $\$ 0.68$ & $\$ 0.74$ & $\$ 0.80$ \\
\hline
\end{tabular}

Every effort level has a cost paid by the worker. For example, the cost of the effort level 0.5 is 28 cents or $\$ 0.28$, located directly under 0.5 in the table. A worker has to pay 80 cents for an effort level of 1 .

Note that a worker earns a wage in ECUs and pays the cost of effort in dollars. The workers payment for a round is the value of their ECU wage minus the cost of effort they pay.

On the next computer practice screen, enter the effort level that costs $\$ 0.24$ Enter the effort level that costs $\$ 0.57$

Click the Submit Effort Answers button.

The amount that an employer earns in one round depends on the wage and the effort of the employee they are matched with.

This is how the employer is compensated: The employer subtracts the wage from 1150 and then multiplies that number by the effort level of the employee.

In one round the employer earns

$$
(1150-\text { wage }) \times \text { effort level }
$$

To do a practice calculation on the next practice screen, first type in a wage. Second, select an effort level. Click the Submit Effort Level button.

Make your practice calculation by subtracting the wage you entered from 1150 (use the calculator if you need it). Then, multiply that number by the effort level you selected.

If the answer you calculate has a number after the decimal point, round your answer. For example, 400.5 rounds up to 401 and 300.2 rounds down to 300 .

Your choices cannot cause the example worker to lose money. If you make a choice that would lead to losing money, a pop up message will notify you. Note that effort costs money.

Enter the profit and then click Submit Profit Calculation. When you enter the correct calculation, you can advance to the next practice screen. Please raise your hand if you have a question and the experimenter will help you.

At the end of the experiment, you will be paid for all 7 rounds. The exchange rate is 1 dollar for every 130 ECUs.

It is possible that there will be a one-time change in the exchange rate or other numbers for the profit calculation between Stage 1 and Stage 2. If that happens, you will be notified.

Do not talk to other participants during the experiment. If you have a question, ask the experimenter.

Review

During a round, employers set a wage and then employees set an effort level. 
Employees earn

$$
\text { wage - cost of effort }
$$

Employers earn

$$
(1150 \text { - wage }) \times \text { effort level of employee }
$$

During the experiment, participants earn experimental currency units (ECU) that are exchanged for dollars at the end based on the exchange rate.

Some questions will be asked after round 5 and after round 7 .

The next screen informs you of your role in the experiment.

Click OK. Next, you will begin Round 1 and employers will set the first wage.

Any further instruction you will need will be on the computer screen. Keep this instruction sheet at your desk for reference. 